\title{
Acolhimento e vínculo no processo de fazer dos agentes comunitários de saúde: Revisão Integrativa
}

\author{
Graziele Gorete Portella da Fonseca* Suzinara Beatriz Soares de

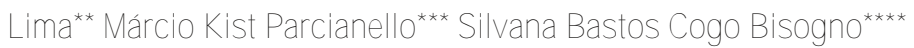

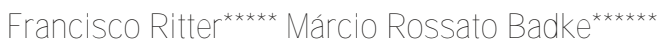

Resumo: Como objetivo deste estudo tem-se analisar as publicações científicas brasileiras da área da saúde acerca dos agentes comunitários de saúde e 0 acolhimento e vínculo no seu fazer cotidiano. Trata-se de uma revisão integrativa realizada na base de dados LILACS e na biblioteca virtual SCIELO, com recorte temporal entre 2003 - 2011. Ao final do estudo percebeu-se a complexidade que envolve 0 fazer do agente comunitário de saúde (ACS), principalmente no que se refere ao acolhimento e vínculo. Contudo, verificou-se que para o agente comunitário de saúde o acolhimento e a criação do vínculo, são ações essenciais no seu labor, e na busca por uma assistência humanizada, educativa e que venham ao encontro das necessidades da comunidade. Todavia, evidenciou-se também a fragilidade existente nas publicações científicas acerca da temática. Portanto, faz-se necessário novos estudos em relação à temática.

Descritores: Agente comunitário de saúde, acolhimento, vínculo.

\section{Reception and bonding in the process of making of community health agents: Integrative Review}

\begin{abstract}
The objective of this study is to analyze scientific publications about the health of the community health agents and your reception and bond in daily. It is an integrative review conducted in the databases SciELO and LILACS, with time among 2003 to 2011. At the end of the study realized the complexity involved in making the community health agent, especially with regard to the reception and bond. However, it was found that for the community health agentthe reception and create the bond, are essential actions in its work, and the search for a humanized, and education that meet community needs. However, there was also a weakness in the existing scientific literature on the subject. Therefore, it is necessary to further studies in relation to the theme.
\end{abstract}

Descriptores: Community health workers, user embracement, bond.

*Especialização em Gestão de Organização Pública em Saúde pela Universidade Federal de Santa Maria (UFSM), Santa Maria, RS, Brasil.

**Pós-doutora em enfermagem pela Universidade Federal de Santa Catarina (UFSC), Florianópolis, RS, Brasil.

***Especialização em Gestão de Organização Pública em Saúde na Universidade Federal de Santa Maria (UFSM), Santa Maria, RS, Brasil.

****Doutoranda em enfermagem na Universidade Federal de Rio Grande (FURG), Rio Grande, RS, Brasil.

*****Doutor em psicologia pela Universidad de Buenos Aires (UBA), Buenos Aires, BA, Argentina.

${ }^{* * * * * *}$ Mestre em enfermagem pela Universidade Federal de Santa Maria (UFSM), Santa Maria, RS, Brasil. 


\section{Introdução}

A Reforma Sanitária foi um marco histórico no decorrer da evolução do setor saúde no Brasil, de modo que seus ideais eram elencados pela busca de direitos igualitários aos serviços de saúde, bem como a implementação de ações de proteção, promoção, recuperação e reabilitação da saúde. Para tanto foi elaborado um documento com as propostas as quais foram discutidas na IX Conferência Nacional de Saúde (CNS) em 1986. Surgindo então uma nova forma de fazer saúde, de forma unificada, e em 1988 é consolidado o Sistema Único de Saúde (SUS) o qual vem para reorientar os serviços, ampliando o conceito de saúde'.

O Brasil passou por profundas transformações e resistências na área da saúde, uma delas foi à de contraposição ao modelo biomédico. Para tanto buscou aliar o serviço, 0 usuário e os trabalhadores num efetivo convívio através do acolhimento e vínculo, buscando concretizar os princípios do Sistema Único de Saúde (SUS). Assim, o acolhimento consiste em uma nova forma de cuidar, que procura aprimorar a qualidade do serviço prestado, estabelecendo relações de potência no processo de produção de saúde, desse modo leva ao reconhecimento do usuário como sujeito ativo e participativo desse processo².

Em 1991, é implantado no Brasil o Programa de Agentes Comunitários de Saúde (PACS), considerado como uma estratégia para o estabelecimento de laços entre a rede de saúde e a população ${ }^{3}$, na intenção de consolidar ainda mais a ideia de reorientar o modelo assistencial, dando maior importância às práticas de promoção da saúde. Em 1994, é criado 0 Programa Saúde da Família (PSF) sendo hoje conhecida como Estratégia da Saúde da Família (ESF) com ações voltadas a uma atenção integral aos usuários, conseguindo com isso oferecer um atendimento humanizado, alcançando um dos objetivos do programa nacional de humanização (PNH) - a melhora do vínculo equipe usuário4.

Sabe-se, que o SUS já evoluiu muito em relação aos programas e ações desde sua criação. O PACS é um exemplo disso, pois, com sua implementação a comunidade teve a garantia de maior acessibilidade à saúde, sendo que o fato do agente comunitário de saúde (ACS) ser uma pessoa integrante da comunidade facilita o acesso em relação à população, criando desta maneira um vínculo de confiança entre profissionais e comunidade.

Diante da consolidação da prática do cuidado de maneira humanizada, em 2003, o Ministério da Saúde lançou o Programa Nacional de Humanização (PNH). Conforme o PNH, humanização é a valorização dos usuários durante o processo de fazer saúde, constituído através das relações equipe, usuários, bem como profissional/equipe ${ }^{2}$. A humanização das relações de usuários e trabalhadores, consequentemente promove a humanização do serviço o qual irá reconhecer o usuário como ser autônomo e singular, procurando atender suas necessidades construindo assim, as relações de acolhimento e, portanto, o vínculo.

A ESF, pelo fato de propor uma nova dinâmica para estruturação dos serviços de saúde voltados a família e a humanização do cuidado, torna-se complexa exigindo a atuação de uma equipe multiprofissional na qual o enfermeiro possui um papel de destaque, pois, é ele quem irá promover formas de integrar e incentivar os membros da equipe a prestarem assistência de forma integral. Possui também o papel de coordenador dos Agentes Comunitários de Saúde articulando formas de intervir junto à comunidade, enfim seu papel é amplo e essencial para a realização de ações, possibilitando a construção de propostas integradas e articuladas a realidade de cada família assistida. 
Nesse interim, o gerenciamento possui papel relevante no processo de trabalho consolidado pelas relações gerentes, equipe, bem como com os usuários, para isso a gestão deve ser focada em sanar as necessidades apresentadas pelos usuários da rede de serviço ${ }^{5}$. Neste sentido o serviço desenvolvido com esse método nos leva a refletir no acolhimento 0 qual é uma forma de tornar a rede mais resolutiva, e consequentemente 0 usuário mais satisfeito.

O acolhimento tem por objetivo otimizar o acesso da demanda ao serviço de saúde, de modo a atender as suas necessidades, de forma humanizada através da comunicação e do ouvir, atendendo o sujeito de maneira integral, conforme a dimensão do seu problema e do grau de tecnologia exigida ${ }^{6}$.

Complementando a ideia o acolhimento propõe a organização e funcionamento do serviço de saúde, através do seguimento dos seguintes princípios: garantia ao acesso de maneira universal, reorganização do processo de trabalho, valorização e qualificação da equipe no intuito de melhorar a relação profissional/usuário por parâmetros humanitários e acolhedores ${ }^{7}$.

$O$ processo de acolhimento entre sujeito e trabalhador de maneira eficaz acarreta no surgimento do vínculo o qual é uma conquista, não um evento imediato. Como tecnologia leve, o acolhimento direciona para a efetivação de estratégias de atendimento envolvendo trabalhadores, usuários e gerentes com a finalidade de aprimorar 0 atendimento e torná-lo resolutivo perante sua demanda ${ }^{8}$.

No entanto vale lembrar que 0 acolhimento é responsabilidade de toda a equipe, pois cada membro possui uma função essencial ao processo. A construção da relação de trabalhadores e usuários depende de ambos, pois a equipe deve saber acolher, já o usuário deve demonstrar empenho e envolvimento para a realização da metodologia ${ }^{6}$.

Portanto, a justificativa desse trabalho consiste na necessidade de conhecer a real situação da efetivação do acolhimento e consequentemente de vínculo no processo de trabalho dos ACSs, visto que esse tipo de serviço consiste no primeiro contato do usuário com os serviços de saúde do SUS. E o que se percebe é que sua eficácia é influenciada pela qualidade do fator humano e do relacionamento que se estabelece entre profissional e usuário ${ }^{5}$.

Justifica-se 0 estudo a fim de subsidiar o profissional de saúde para efetivar na prática uma abordagem de qualidade perante os usuários, e por ser o ACS integrante de uma equipe, o mesmo é um mediador para que a qualidade se estabeleça no seu âmbito de atuação. Acredita-se que, com a aquisição desses subsídios poderemos desenvolver uma equipe tecnicamente competente e humanamente engajada e comprometida com as necessidades da população.

No decorrer dos últimos vinte anos o Brasil passou por profundas transformações, em especial no sistema público de saúde. De modo que o SUS investiu na reorganização da rede de serviços, ampliando e fortalecendo a atenção básica por meio da ampliação do acesso, da qualidade dos trabalhadores, e da humanização dos serviços prestados. Além disso, o SUS passou a contar com vários programas e políticas de saúde, o que permite constituir novos modos de cuidar, de acordo com a base discursiva do Sistema Único de Saúde. Ao encontro disso está a prática do acolhimento entre trabalhadores e usuários que possibilita construir uma nova forma de cuidar, procurando satisfazer as necessidades da demanda ${ }^{10}$. O SUS ao Rev. Saúde (Santa Maria), Santa Maria, v.39, n.2. p.09-22, Jul./Dez.2013. Fonseca, G. G. P.; et al. longo de sua trajetória e consolidação conquistou muitos avanços para a saúde da população 
brasileira, no entanto, enfrenta naturalmente vários desafios no processo de fazer. Nesse sentido, o acolhimento auxilia na defesa do SUS na medida em que possibilita a construção de uma aliança entre serviços e usuários, de maneira a deixar o sistema mais forte e eficaz².

0 acolhimento tem por objetivo otimizar o acesso da demanda ao serviço de saúde, de modo a atender as suas necessidades, de forma humanizada através da comunicação e do ouvir, atendendo o sujeito de maneira integral, conforme a dimensão do seu problema e do grau de tecnologia exigida ${ }^{7}$.

Complementando a ideia 0 acolhimento propõe a organização e funcionamento do serviço de saúde, através do seguimento dos seguintes princípios: garantia ao acesso de maneira universal, reorganização do processo de trabalho, valorização e qualificação da equipe no intuito de melhorar a relação profissional/usuário por parâmetros humanitários e acolhedores ${ }^{8}$

0 processo de acolhimento entre sujeito e trabalhador de maneira eficaz acarretando no surgimento do vínculo o qual é uma conquista, não um evento imediato. Como tecnologia leve, o acolhimento direciona para a efetivação de estratégias de atendimento envolvendo trabalhadores, usuários e gerentes com a finalidade de aprimorar 0 atendimento e torná-lo resolutivo perante sua demanda ${ }^{9}$.

No entanto vale lembrar que o acolhimento é responsabilidade de toda a equipe, pois cada membro possui uma função essencial ao processo. A construção da relação de trabalhadores e usuários depende de ambos, pois a equipe deve saber acolher e 0 usuário carece corroborar para a realização da metodologia ${ }^{7}$.

Nesse interim, o gerenciamento possui papel relevante no processo de trabalho consolidado pelas relações gerentes, equipe, bem como com os usuários, para isso a gestão deve ser focada em sanar as necessidades apresentadas pelos usuários da rede de serviço ${ }^{10}$. Neste sentido o serviço desenvolvido com esse método nos leva a refletir no acolhimento 0 qual é uma forma de tornar a rede mais resolutiva, e consequentemente 0 usuário mais satisfeito.

Diante desta problemática, a questão norteadora desta pesquisa é: qual o conhecimento científico produzido na área da saúde acerca da temática dos ACS com o acolhimento e vínculo? Frente ao questionamento, este trabalho tem como objetivo analisar as publicações científicas brasileiras da área da saúde acerca dos agentes comunitários de saúde e 0 acolhimento e vínculo no seu fazer cotidiano.

Portanto, o acolhimento auxilia na defesa do SUS na medida em que possibilita a construção de uma aliança entre serviços e usuários, de maneira a deixar o sistema mais forte e eficaz ${ }^{2}$.

A partir desta problemática, a questão norteadora desta pesquisa é: qual o conhecimento produzido em saúde a cerca do acolhimento realizado por Agentes Comunitários de Saúde? Frente ao questionamento, este trabalho tem como objetivo analisar as publicações científicas brasileiras da área da saúde acerca dos agentes comunitários de saúde e o acolhimento e vínculo no seu fazer cotidiano. 


\section{Metodologia}

Trata-se de uma pesquisa qualitativo-exploratória de caráter bibliográfica do tipo revisão integrativa, a qual é um método de pesquisa que permite a incorporação das evidências na prática clínica com 0 intuito de reunir e sintetizar resultados de pesquisa sobre determinado assunto, tema ou questão, de maneira sistemática e ordenada ${ }^{11}$. A busca de produções científicas foi realizada na biblioteca virtual em saúde (BVS- BIREME), pela base de dados: Literatura Latino- Americana e do Caribe em Ciências da Saúda (LILACS) e na biblioteca virtual Scientific Eletronic Library Online (SCIELO). Optou-se pela busca em somente duas fontes de dados, devido ao curto período de tempo existente para a elaboração deste trabalho. Essa busca procedeu-se no mês de setembro do ano de 2012. Para a coleta de dados foram utilizadas individualmente as seguintes palavras-chave: Agentes comunitários de saúde, acolhimento, vínculo. Determinou-se então os critérios de exclusão/ inclusão por meio da literatura, com a delimitação temporal a qual foi de 2003 a 2011, por ter sido em 20030 início da Política Nacional de Humanização, no qual o acolhimento apresenta-se como uma de suas diretrizes.

Os critérios de inclusão foram: artigos, dissertações e teses disponibilizados em texto completo em suporte eletrônico, publicado em periódicos nacional. Assim os critérios de exclusão foram: livros, capítulos de livros, anais de congressos ou conferências, relatórios técnicos e científicos e documentos ministeriais, bem como os periódicos estrangeiros e os que não estavam disponíveis na íntegra.

Para análise e posterior síntese do material científico encontrado, construiu-se um quadro sinóptico, o qual contemplou os aspectos considerados pertinentes: local, ano e fonte, autores, titulo, objetivos, metodologia e resultados. Assim, na análise foi utilizada a análise de conteúdo, que conta com três etapas: pré-análise, exploração do material e interpretação dos resultados $^{12}$. A primeira etapa é a leitura flutuante, sendo necessário ler mais de uma vez 0 material, para apropriação dos dados. $\mathrm{Na}$ etapa de exploração dos dados foi realizada a caracterização das produções na elaboração de uma ficha analítica para a extração de dados composta pelos itens: local, ano e fonte, objetivos, metodologia e resultados. Essa etapa de exploração do material foi desenvolvida com uma leitura exaustiva dos textos, e a partir disso emergiu as unidades de significados.

Para interpretação dos resultados foram elaboradas categorias temáticas nos achados que apresentaram significância de elementos comuns de maior incidência no material científico encontrado e convergência com a temática proposta. A partir da análise sintética dos textos foi realizada a etapa e interpretação dos resultados relacionando-os aos referenciais teóricos. Nesta fase foram elaboradas três categorias: $\mathrm{O}$ ser agente comunitário de saúde que busca o vínculo; A formação do agente comunitário de saúde acerca do acolhimento e vínculo; A prática do agente comunitário de saúde no contexto da ESF.

\section{Discussão}

Os resultados desta pesquisa foram obtidos após a realização de uma busca na LILACS e na SCIELO, e assim obteve-se após o uso dos critérios de inclusão e exclusão um total de 10 artigos na íntegra. Foram caracterizadas em um quadro apresentado logo abaixo as

Rev. Saúde (Santa Maria), Santa Maria, v.39, n.2 p.09-22, Jul./Dez.2013. Fonseca, G. G. P. et al. ISSN 2236-5843 
produções conforme a área, sendo: 4 da enfermagem; 6 multidisciplinares, sendo que estes com abordagens de enfermagem, medicina, psicologia, terapia ocupacional e odontologia . Quanto ao método do estudo foram 5 qualitativos, um com abordagem fenomenológica, um com abordagem histórico- social e crítico- analítica, um relato de caso, um Exploratório e descritivo e um descritivo de caráter qualitativo. 0 cenário de desenvolvimento dos mesmos na grande maioria foi o SUS, mais especificamente em unidades básicas de saúde contempladas por ESF.

Os estudos apresentaram como sujeito os agentes comunitários de saúde e o seu fazer. Destacaram-se assim as categorias temáticas: $O$ ser agente comunitário de saúde que busca o vínculo; A formação do agente comunitário de saúde acerca do acolhimento e vínculo; $A$ prática do agente comunitário de saúde no contexto da ESF.

A partir da busca realizada no banco de dados da BVS (LILACS e SCIELO) com 0 descritor agente comunitário de saúde encontrou-se 348 trabalhos referentes à temática, destes selecionou-se 49 artigos que então após leitura minuciosa aproveitou-se apenas 4 artigos. Em outra tentativa utilizou-se 0 descritor acolhimento, então se encontrou 405 trabalhos, dos quais se selecionou 10 artigos, e após leitura elegeu-se somente 3 artigos, pois melhor enquadravam-se ao objeto de pesquisa, já com o descritor vínculo encontrou-se 157 trabalhos dos quais foram selecionados 8 artigos, mas foram utilizados apenas 3 , assim elegeu-se os 10 artigos mais relevantes ao assunto e que se enquadravam nos critérios de inclusão, pois eram artigos, dissertações e teses disponibilizados em texto completo e em suporte eletrônico, bem como publicados em periódicos nacionais, na língua portuguesa entre os anos de 2003 e 2011. Abaixo se apresenta o quadro que ilustra os artigos selecionados para o desenvolvimento desta pesquisa.

\begin{tabular}{|c|c|c|c|c|c|}
\hline $\begin{array}{l}\text { Local; Ano; } \\
\text { Fonte }\end{array}$ & ; $\quad$ Autor (es) & Título & Objetivos & Metodologia & Resultados \\
\hline $\begin{array}{l}\text { 1. Rio de } \\
\text { Janeiro, } \\
\text { 2011; } \\
\text { Physis- } \\
\text { Revista de } \\
\text { saúde } \\
\text { coletiva }\end{array}$ & $\begin{array}{l}\text { BARALHA } \\
\text { S, M.; } \\
\text { PEREIRA, } \\
\text { M. A. O. }\end{array}$ & $\begin{array}{l}\text { Concepções dos } \\
\text { agentes } \\
\text { comunitários de } \\
\text { saúde sobre suas } \\
\text { práticas } \\
\text { assistenciais. }\end{array}$ & $\begin{array}{c}\text { Busca Identificar as } \\
\text { representações elaboradas } \\
\text { por agentes comunitários de } \\
\text { saúde (ACS) acerca de suas } \\
\text { praticas assistenciais. }\end{array}$ & Qualitativa & $\begin{array}{c}\text { Os resultados } \\
\text { mostraram que os ACS } \\
\text { acreditam ser relevante } \\
\text { a criação e } \\
\text { manutenção do vinculo, } \\
\text { mas ainda apresentam } \\
\text { uma fragilidade nas } \\
\text { suas praticas } \\
\text { assistenciais. }\end{array}$ \\
\hline $\begin{array}{l}\text { 2. Rio de } \\
\text { Janeiro; } \\
\text { 2008; Ciênc. } \\
\text { saúde } \\
\text { coletiva. }\end{array}$ & $\begin{array}{l}\text { BACHILLI, } \\
\text { R. G.; } \\
\text { SCAVASSA, } \\
\text { A. J.; SPIRI, } \\
\text { W. C. }\end{array}$ & $\begin{array}{l}\text { A identidade do } \\
\text { agente } \\
\text { comunitário de } \\
\text { saúde: uma } \\
\text { abordagem } \\
\text { fenomenológica. }\end{array}$ & $\begin{array}{l}\text { Compreender os fatores } \\
\text { psicossociais, segundo as } \\
\text { perspectivas destes } \\
\text { agentes, que são } \\
\text { significativos na construção } \\
\text { de sua identidade. }\end{array}$ & $\begin{array}{c}\text { Fenomenolo } \\
\text { gia } \\
\text { hermenêutica } \\
\text { de Paul } \\
\text { Ricoeur. }\end{array}$ & $\begin{array}{l}\text { Evidenciou-se que } \\
\text { toda a trajetória do } \\
\text { agente referente ao } \\
\text { serviço de saúde e sua } \\
\text { preparação para atuar } \\
\text { ali, bem como a } \\
\text { importância que o } \\
\text { mesmo atribui ao } \\
\text { cotidiano de trabalho, } \\
\text { atribuindo ao ato à } \\
\text { oportunidade de } \\
\text { desvelar necessidades } \\
\text { e dúvidas do usuário } \\
\text { por meio da escuta }\end{array}$ \\
\hline
\end{tabular}


do dialogo, sendo que

assim afirmam

fortalecer o vinculo com

a comunidade, com

isso contribuindo ainda

mais com a resolução

do sistema.

\begin{tabular}{cccc}
\hline 3. Rio de & NASCl & Agente & Identificar as contribuições \\
Janeiro; & MENTO, E. & comunitário de & que o curso de formação de \\
2008; Cad. & P.L.; & saúde: formação, & agente comunitário de \\
Saúde & CORREA, & inserção e prática. & saúde oferecido pela \\
Pública & C.R. S. & secretaria municipal de \\
& & saúde de Campinas, São \\
& & Paulo, Brasil nos anos 2001 \\
& & a 2003, para a avaliação \\
& & que esses fazem da sua \\
& & inserção no território, bem \\
& & como apontar o impacto que \\
& & teve na sua pratica \\
& & profissional.
\end{tabular}

Qualitativa

Constatou-se que a

formação possibilitou

que 0 agente

comunitário de saúde

assumisse o papel de

sujeito educativo

produzindo um

conhecimento

emancipatório,

estimulando a reflexão

e a capacidade de

análise crítica,

incluindo a prática

diária, na qual valoriza

muito a prática do

acolhimento e vinculo

aos usuários.

\begin{tabular}{l}
\hline 4. Rio de \\
Janeiro, \\
2009; \\
Dissertação- \\
BVS.
\end{tabular}

SCHMIDE
L, J.P. C.

seord

Formação do

comunitário de

saúde na

reorganização da

atenção primária

com perspectiva

de mudança do

modelo de

atenção.

Analisar a percepção do

agente comunitário de

saúde sobre a formação

recebida em relação às

competências necessárias

para o desenvolvimento do

trabalho em equipe na

Estratégia Saúde da

Família, bem como

Identificar os objetivos e os

princípios metodológicos do curso do Agente

Comunitário de Saúde;

descrever a percepção dos

Agentes Comunitários de

Saúde sobre a formação

recebida, e de que modo

constroem os conceitos de

saúde e de promoção de

saúde; identificar as práticas

de saúde dos Agentes

Comunitários de Saúde na

abordagem individual $\mathrm{e}$

coletiva aos usuários e os

serviços de saúde; Propor

estratégias que subsidiem a

formação dos Agentes

Comunitários de Saúde,

dentro da perspectiva da

competência.
Trata-se de uma pesquisa

qualitativa.

Evidenciou-se que

este profissional

visualiza a saúde de

maneira ampliada, e

que sua forma de

trabalho enfoca a

acessibilidade, 0

acolhimento e 0

trabalho em equipe, em bora apresentam um certo distanciamento acerca do restante da equipe.
Rev. Saúde (Santa Maria), Santa Maria, v.39, n.2 p.09-22, Jul./Dez.2013.

Fonseca, G. G. P.; et al. 
5. Rio de GALAVOTE Desvendando os Avaliar a produção dos Janeiro; , H. S.; processos de processos de trabalho dos 2011; Ciênc. PRADO, T. trabalho do agente ACSs na Estratégia Saúde Saúde N.; MACIEL, comunitário de da Família no município de coletiva.

$\begin{array}{cc}\text { E. L. N.; } & \text { saúde nos } \\ \text { LIMA, R. C. } & \text { cenários revelados } \\ \text { D. } & \text { na Estratégia } \\ & \text { Saúde da Família } \\ & \text { no município de } \\ \text { Vitória (ES, } \\ \text { Brasil). }\end{array}$

Descritivo de Segundo os agentes caráter comunitários de saúde, qualitativo. o processo de trabalho em saúde é considerado como sendo a prevenção e promoção da saúde. Segundo eles 0 acolhimento é ouvi o outro, é identificar a necessidade do usuário, sendo que os mesmos lamentam não haver no serviço a pratica efetiva do acolhimento e consequentemente do vinculo.

\begin{tabular}{|c|c|c|c|c|c|}
\hline $\begin{array}{l}\text { 6. Rio de } \\
\text { janeiro; } \\
\text { 2004; } \\
\text { Dissertação. } \\
\text { BVS. }\end{array}$ & $\begin{array}{l}\text { LUNARDE } \\
\text { LO, S. R. }\end{array}$ & $\begin{array}{l}\text { O trabalho do } \\
\text { agente } \\
\text { comunitário de } \\
\text { saúde nos núcleos } \\
\text { de saúde da } \\
\text { família em } \\
\text { Ribeirão Preto- } \\
\text { São Paulo. }\end{array}$ & $\begin{array}{c}\text { Busca caracterizar o } \\
\text { agente comunitário de } \\
\text { saúde dos núcleos de saúde } \\
\text { da família ligados ao Centro } \\
\text { de Saúde Escola da } \\
\text { Faculdade de Medicina de } \\
\text { Ribeirão Preto- USP, bem } \\
\text { como identificar as } \\
\text { repercussões que o } \\
\text { desenvolver deste trabalho } \\
\text { tem Ihe trazido. }\end{array}$ & $\begin{array}{c}\text { Exploratório e } \\
\text { descritivo. }\end{array}$ & $\begin{array}{l}\text { Identificou-se que } \\
\text { este profissional } \\
\text { executa um trabalho } \\
\text { complexo, e por este } \\
\text { motivo, utilizam-se no } \\
\text { seu trabalho de } \\
\text { ferramentas leves } \\
\text { como o acolhimento, o } \\
\text { respeito, o vinculo, no } \\
\text { intuito de colaborar na } \\
\text { construção de um novo } \\
\text { modelo assistencial } \\
\text { voltado a atenção à } \\
\text { saúde humanizada. }\end{array}$ \\
\hline $\begin{array}{l}\text { 7. Rio de } \\
\text { Janeiro; } \\
\text { 2009; Cad. } \\
\text { Saúde } \\
\text { publica. }\end{array}$ & $\begin{array}{l}\text { FERREIR } \\
\text { A, V. S. C.; } \\
\text { ANDRADE, } \\
\text { C. S.; } \\
\text { FRANCO, T. } \\
\text { B.; MERHY, } \\
\text { E. E. }\end{array}$ & $\begin{array}{l}\text { Processo de } \\
\text { trabalho do agente } \\
\text { comunitário de } \\
\text { saúde e a } \\
\text { reestruturação } \\
\text { produtiva. }\end{array}$ & $\begin{array}{l}\text { Analisa a produção do } \\
\text { cuidado pelo agente } \\
\text { comunitário de saúde (ACS) } \\
\text { na saúde da família, tendo } \\
\text { como marcadores seu } \\
\text { processo de trabalho, as } \\
\text { tecnologias de cuidado e a } \\
\text { caracterização da } \\
\text { reestruturação produtiva. }\end{array}$ & $\begin{array}{l}\text { Trata-se de } \\
\text { um relato de } \\
\text { caso. }\end{array}$ & $\begin{array}{c}\text { Os resultados } \\
\text { mostram que os ACS } \\
\text { exercem seu trabalho } \\
\text { centrado nas } \\
\text { tecnologias leves e } \\
\text { leve-duras, as quais se } \\
\text { constituem na escuta, } \\
\text { dialogo, enfim nas } \\
\text { relações, promovendo } \\
\text { deste modo o vinculo e } \\
\text { o acolhimento a } \\
\text { comunidade e clientela, } \\
\text { mas que apenas o ACS } \\
\text { não conseguem uma } \\
\text { reestruturação } \\
\text { produtiva no PSF. }\end{array}$ \\
\hline
\end{tabular}

Saúde (Santa Maria), v.39, n.2, p.09-22, 2013. Acolhimento e vinculo no processo de fazer dos agentes comunitários de saúde: Revisão Integrativa 
8. Rio de RODRIGU Agente Objetivou analisar o Abordagem Evidenciou-se que 0

Janeiro; 2010; ES, A. A. A. comunitário de papel do agente histórica- agente comunitário de Ciênc. Saúde $\quad$ O.; saúde: sujeito da comunitário de saúde no social e critico- saúde integrante da coletiva. SANTOS, A. prática em saúde cotidiano da equipe e analítica. equipe de saúde bucal M.; ASSIS, bucal em saúde bucal no programa

M. M. A. Alagoinhas, Bahia. de saúde da família em realiza atividades de acolher, informar, Alagoinhas (BA), considerando a construção de saberes e práticas relacionadas ao campo a saúde coletiva. atender e encaminhar os usuários, com isso estes profissionais se destacam como sujeito social/coletivo.

\begin{tabular}{|c|c|c|c|c|c|}
\hline $\begin{array}{l}\text { 9. Rio de } \\
\text { Janeiro; 2009; } \\
\text { Ciênc. Saúde } \\
\text { coletiva. }\end{array}$ & $\begin{array}{l}\text { BARROS, } \\
\text { M. M. M.; } \\
\text { CHAGAS, } \\
\text { M. I. O.; } \\
\text { DIAS, M. S. } \\
\text { A. }\end{array}$ & $\begin{array}{l}\text { Saberes e } \\
\text { práticas do agente } \\
\text { comunitário de } \\
\text { saúde no universo } \\
\text { do transtorno } \\
\text { mental. }\end{array}$ & $\begin{array}{l}\text { Objetivou conhecer os } \\
\text { saberes e práticas do } \\
\text { agente comunitário de } \\
\text { saúde no universo do } \\
\text { transtorno mental. }\end{array}$ & $\begin{array}{l}\text { Investigação } \\
\text { de natureza } \\
\text { qualitativa. }\end{array}$ & $\begin{array}{l}\text { Evidenciou-se que } \\
\text { este profissional, } \\
\text { embora possua } \\
\text { algumas dificuldades } \\
\text { quanto ao exercício da } \\
\text { profissão referente ao } \\
\text { transtorno mental, } \\
\text { busca estratégias como } \\
\text { o diálogo para } \\
\text { conseguir exercer e } \\
\text { otimizar seu trabalho } \\
\text { frente a clientes com } \\
\text { transtornos mentais, } \\
\text { bem como seus } \\
\text { familiares, } \\
\text { proporcionando assim } \\
\text { um vinculo entre eles. }\end{array}$ \\
\hline $\begin{array}{l}\text { 10. Juíz de } \\
\text { Fora; 2010; } \\
\text { Revista APS }\end{array}$ & $\begin{array}{l}\text { DANTAS } \\
\text { MBP, SILVA } \\
\text { MRF, } \\
\text { FELICIAN- } \\
\text { O KVO. }\end{array}$ & $\begin{array}{l}\text { Subjetividade e } \\
\text { dialogo na } \\
\text { educação em } \\
\text { saúde: práticas de } \\
\text { agentes } \\
\text { comunitários em } \\
\text { equipe de saúde } \\
\text { da família. }\end{array}$ & $\begin{array}{c}\text { Refletir sobre as } \\
\text { concepções e as práticas } \\
\text { de educação em saúde } \\
\text { de agentes comunitários } \\
\text { (ACS) em uma unidade } \\
\text { da estratégia saúde da } \\
\text { família (ESF) no } \\
\text { município de João } \\
\text { Pessoa, no que diz } \\
\text { respeito ao diálogo e à } \\
\text { (inter) subjetividade. }\end{array}$ & Qualitativa & $\begin{array}{c}\text { Os resultados } \\
\text { evidenciaram a } \\
\text { valorização por parte } \\
\text { dos ACS do vínculo e } \\
\text { dos elementos } \\
\text { constituintes do } \\
\text { acolhimento, aqui } \\
\text { evidenciado pela } \\
\text { confiança, prática } \\
\text { dialógica e } \\
\text { participativa. No } \\
\text { entanto evidenciou-se } \\
\text { a necessidade de } \\
\text { mudança na } \\
\text { organização do } \\
\text { trabalho e a assistência } \\
\text { para a otimização e } \\
\text { ampliação das ações } \\
\text { educativas. }\end{array}$ \\
\hline
\end{tabular}


A seguir aborda-se os artigos 1 e 2 na categoria: 0 ser agente comunitário de saúde que busca 0 vínculo, que está presente no artigo de Baralhas e Pereira ${ }^{13}$ (2011), os quais trazem as concepções dos agentes comunitários de saúde sobre suas práticas assistenciais, que segundo os mesmos, são pautadas na busca pela construção de laços de confiança (vínculo), no intuito da promoção da saúde e na prevenção de doenças. Dessa maneira 0 ACS é o trabalhador de destaque na construção do vínculo entre comunidade e serviço de saúde, pois é considerado o elo entre estes. Assim suas práticas são responsáveis pelo vínculo existente entre comunidade e profissionais ${ }^{14}$.

Já 0 artigo de Bachilli, Scavassa, Spiri15 (2008), busca compreender os fatores psicossociais, segundo as perspectivas dos agentes, e os que são significativos na construção de sua identidade, a qual é formada por constantes mudanças e lutas, e por isso atribuem enorme importância ao seu cotidiano de labor, por ser este o momento que possuem para escutar, dialogar e assim fortalecer o vínculo com a comunidade. O ACS é o principal elo entre o serviço de saúde e a população, sendo estes considerados protagonistas da relação de troca estabelecida entre ambos ${ }^{16}$.

O ACS é um agente transformador na medida em que ao conhecer a realidade e as reais necessidades da comunidade, tem a possibilidade de educar, orientar, bem como fazer a mediação com o serviço, proporcionando assim a melhora na qualidade de vida e da saúde da população. Assim, o ACS ao mesmo tempo em que, transforma também é transformado, pois ao transformar a comunidade se auto transforma, uma vez que também reside ali ${ }^{14}$.

A categoria: A formação do agente comunitário de saúde acerca do acolhimento e vínculo, presente no artigo de Nascimento e Correa ${ }^{17}$ (2008) discutem acerca do agente comunitário de saúde: formação, inserção e prática, onde trazem que os ACS estabelecem vínculo, ouvem e buscam ajudar o usuário e sua família a sanar suas necessidades, objetivando um pleno bem estar a eles. Dessa forma, conclui-se que a formação oferecida aos ACSs é determinante na construção da habilidade e competências, que possibilitam construírem espaços de trocas e cumplicidade da comunidade com o serviço de saúde e estabelecendo desta maneira o vínculo entre ambos.

Nessa perspectiva, 0 acolhimento tem 0 objetivo de fazer uma escuta qualificada e buscar a melhor solução para a situação apresentada ${ }^{18}$. Destaca-se ainda que para se efetivar a implantação do SUS, incluindo as práticas efetivas do acolhimento, é necessário capacitar os recursos humanos em saúde, como por exemplo, os ACS ${ }^{19}$.

Na pesquisa de Schmidel20 (2009), discute-se a formação do agente comunitário de saúde na reorganização da atenção primária com perspectiva de mudança do modelo de atenção, e busca analisar a percepção do ACS acerca da formação recebida e a possibilidade da utilização desta pela mudança do processo de trabalho. Evidenciou-se então que, no processo de formação o eixo central do trabalho consiste na busca por acolhimento, acessibilidade e trabalho em equipe. Além disso, no processo de trabalho apresentado, evidenciou-se uma atuação distanciada das barreiras organizacionais, revelando a necessidade de uma maior interação entre ACS e o restante da equipe, para melhor planejar ações, e no intuito de melhorar o serviço frente à comunidade.

Desse modo o conhecimento exigido no processo de trabalho do ACS é bastante

Saúde (Santa Maria), v.39, n.2, p.09-22, 2013. Acolhimento e vinculo no processo de fazer dos agentes comunitários de saúde: Revisão Integrativa complexo e diversificado, e assim transcendem o campo da saúde, pois requererem a aprendizagem de aspectos que estão presentes nas condições socioeconômicas da população atendida. Para tanto exige uma formação inovadora, reflexiva, crítica e transversal (com a capacidade de trabalho em equipe, bem como acerca da relevância da comunicação), para melhorara mediação entre o serviço de saúde e a população21. 
A prática do agente comunitário de saúde no contexto da ESF, o artigo desenvolvido por Galavote, Prado, Maciel, Lima22(2011), buscou avaliar os processos de trabalho dos ACSs na Estratégia Saúde da Família. Os achados revelaram que para os ACSs o processo de trabalho, é a realização de prevenção e promoção da saúde, e que isso na grande maioria das vezes é alcançado por meio do acolhimento destes indivíduos e de sua família. Entretanto, lamentam que o acolhimento não esteja 100\% implantado em seus locais de trabalho, as ESF.

$O$ processo de trabalho torna-se mais qualificado e resolutivo em conjunto com ações voltadas ao acolhimento, uma vez que 0 ato de acolher fortalece o Programa de Saúde da Família (PSF), pois mobiliza a sensibilidade dos profissionais, requerendo uma ação reflexiva, desenvolvimento ético e solidário para escutar e dialogar, valorizando desta maneira o ser humano e cidadão, usuário do serviço23. Dessa maneira, torna-se evidente a relevância da adesão pelos serviços de saúde de ações como 0 ato de acolher o seu usuário.

Já a pesquisa de Lunardelo ${ }^{24}$ (2004), discute o trabalho do agente comunitário de saúde nos núcleos de saúde da família de Ribeirão Preto, então evidenciou-se que, este profissional executa um trabalho complexo, e por este motivo, utiliza-se no seu trabalho de ferramentas leves como 0 acolhimento, o respeito, o vínculo, no intuito de colaborar na construção de um novo modelo assistencial voltado a atenção à saúde humanizada.

Nesse interim o acolhimento busca ampliar e qualificar o acesso da comunidade usuária, humanizando 0 atendimento nos setores de saúde. Assim, acolher é mais do que realizar uma triagem qualificada ou uma escuta interessada, pressupondo um conjunto composto por atividades de escuta, identificação de problemas e ações resolutivas para seu enfrentamento, de maneira a possibilitar a reorganização do modelo assistencial de saúde ${ }^{25}$.

0 artigo discutido por Ferreira, Andrade, Franco e Merhy ${ }^{26}$ (2009), traz o processo de trabalho do agente comunitário de saúde e a reestruturação produtiva. Os resultados apontaram que os ACS exercem o trabalho voltado à escuta, e diálogo, valorizando assim as relações com os usuários por meio do vínculo e do acolhimento, mas que somente este profissional não conseguirá produzir um processo de reestruturação produtivo no PSF. Dessa maneira, o acolhimento implica no estabelecimento de relação (vinculo) de aproximação de forma humanizada. Assim, a existência de uma relação boa entre os profissionais e a comunidade faz a diferença entre as práticas e ações em saúde afirmam ${ }^{27}$.

O artigo de Rodrigues, Santos; Assis ${ }^{28}$ (2010) trazem o agente comunitário de saúde: sujeito da prática em saúde bucal. Evidenciou-se que as ESF exercem um esforço na tentativa de reorganizar o processo de trabalho, assim surge a figura do agente comunitário de saúde integrante da equipe de saúde bucal, o qual realiza atividades de acolher, informar, atender e encaminhar os usuários, com isso estes profissionais se destacam como sujeito social/coletivo.

Exatamente pelo fato de os ACS estarem próximos da comunidade são maiores as possibilidades de realizarem ações e estratégias que proporcionem transformações efetivas no processo e prática de saúde, de maneira que são uma importante ferramenta na reorganização do sistema de saúde, e principalmente na proposta da ESF${ }^{29}$.

O artigo de Barros; Chagas; Dias ${ }^{30}$ (2009) discute os saberes e práticas do agente comunitário de saúde no universo do transtorno mental. Evidenciou-se que este profissional, embora possua algumas dificuldades quanto ao exercício da profissão referente ao transtorno mental, busca estratégias como o diálogo para conseguir exercer e manter o vínculo frente a

Rev. Saúde (Santa Maria), Santa Maria, v.39, n.2 p.09-22, Jul./Dez.2013. Fonseca, G. G. P.; et al. 
clientes com transtornos mentais, bem como seus familiares, fortalecendo e melhorando a atenção a saúde mental, bem como fortalecendo o serviço de saúde (ESF, CAPS, RAISM), na busca pela consolidação da reforma psiquiátrica.

Por ser o SUS um direito de todos, requer dos profissionais atuantes nele uma postura capaz de acolher, escutar, compreender as demandas e necessidades apresentadas. Faz- se necessário também a capacitação desses profissionais, bem como 0 apoio das equipes atuantes em serviço de saúde mental vinculados as ESF, afinal a atenção básica não possui tecnologias suficientes para a resolução de determinadas situações como esta no trabalho de Harada e Soares ${ }^{31}$.

No artigo de Dantas, Silva e Feliciano ${ }^{32}$ (2010), estes debatem a subjetividade e diálogo na educação em saúde: práticas de agentes comunitários em equipe de saúde da família, onde os resultados evidenciaram que a valorização do vínculo e dos elementos constituintes do acolhimento, aqui representados pela confiança, prática dialógica e participativa. No entanto evidenciou-se a necessidade de mudança na organização do trabalho e assistência no intuito de ampliar e aperfeiçoar as ações educativas.

Neste contexto, educação em saúde consiste na combinação de experiências, aprendizagem com vistas a facilitar ações que conduzem à saúde, voltado a instrumentalização de pessoas quanto ao controle e prevenção de doenças, bem como a melhora do bem estar. Para tanto, os ACS necessitam orientar e informar a comunidade quanto à prevenção de doenças e a promoção da saúde, de maneira a exercer um cuidado educativo ${ }^{33}$.

A partir da troca de conhecimentos, valores e crenças, as equipes de saúde e principalmente o ACS por interagir muito com a comunidade, possibilita a ampliação e fortalecimento do vínculo existente entre população e setor saúde, mas principalmente viabiliza a saúde e a qualidade de vida deste usuário.

\section{Conclusão}

Ao término deste estudo, percebeu-se a complexidade que envolve o fazer do ACS, principalmente no que se refere ao acolhimento e vínculo. Contudo, verificou-se que para 0 ACS o acolhimento e a criação do vínculo, são ações essenciais no seu labor, e na busca por uma assistência humanizada, educativa e que venham ao encontro das necessidades da comunidade.

Todavia, pode-se observar pelos resultados obtidos no momento da busca, a carência de publicação no que se refere a estudos acerca do acolhimento e vínculo no fazer do ACS, pois conforme o corte temporal de 2003-2011 selecionaram-se a produção total de 10 trabalhos, sendo duas dissertações. Assim, evidenciou-se a fragilidade existente acerca da temática na produção científica brasileira.

Portanto, fazem-se necessários novos estudos em relação à temática, uma vez que, o ACS é o elo entre serviço e comunidade é de suma importância a manutenção e fortalecimento do vínculo, mas para isso é relevante ações de acolhimento, ou seja, que acolham, ouçam e orientem o sujeito usuário do SUS. 


\section{Referências Bibliográficas}

1. Brasil. Ministério da Saúde. Secretaria de Vigilância em Saúde. Programa Nacional de DST e aids. Oficina de Aconselhamento em DST/ HIV/aids para Atenção Básica. Ministério da Saúde, Secretaria de Vigilância em Saúde, Programa Nacional de DST e Aids. Brasília: Ministério da Saúde, 2005.

2. Brasil. Ministério da Saúde. Secretaria de atenção à saúde. Núcleo técnico da Política Nacional de Humanização. Acolhimento nas práticas de promoção de saúde. 2 ed. Brasília, Editora do Ministério da Saúde, 2008.

3. Santos SMR, Jesus MCP, Amaral, AMM, Costa DMN, Arcanjo RA. A consulta de enfermagem no contexto da atenção básica de saúde, Juiz de Fora, Minas Gerais. Texto contexto-enferm. 2008;17(1):124-30.

4. Ogata MN, Machado MLT, Catoia EA. Saúde da Família como estratégia para mudança do modelo de atenção: representações sociais dos usuários. Rev Eletr Enferm. 2008;11(4):820-29.

5. Fernandes MC, Barros AS, Silva LMS, Nobrega MFB, Silva MRF, Torres RAM. Análise da atuação do enfermeiro na gerencia de Unidades Básicas de Saúde. Rev bras enferm. 2010;63(1):11-15.

6. Oliveira A, Neto JCS, Machado MLT, Souza MBB, Feliciano AB, Ogata MN. A comunicação no contexto do acolhimento em uma unidade de saúde da família de São Carlos, SP. Rev Interface- Comunicação, Saúde, Educação. 2008;12(27):749-62.

7. Merhy EE. Um dos grandes desafios para os gestores do SUS: apostar em novos modos de fabricar os modelos de atenção. In: Merhy E, et al. (Org.) O trabalho de saúde: olhando e experienciando o SUS no cotidiano. São Paulo: Hucitec, 2003.

8. Coelho MO, Jorge MSB. Tecnologia das relações como dispositivo do atendimento humanizado na atenção básica à saúde na perspectiva do acesso, do acolhimento e do vinculo. Ciên Saúde Coletiva. 2009;14, suple1, 1523-31.

9. Merhy EE. Engravidando as palavras: o caso da integralidade. In: Pinheiro R, Mattos R. Construção social da demanda. Rio de Janeiro: IMS-UERJ/ Abrasco, 2005.

10. Pasche DF. Política Nacional de Humanização como aposta na produção coletiva de mudanças nos modos de gerir e cuidar. Interface (Botucatu), Botucatu. 2009; 13, supl.1, 701-08.

11. Mendes KDS, Silveira RCCP, Galvão CM. Revisão integrativa: método de pesquisa para a incorporação de evidencias na saúde e na enfermagem. Texto \& contexto enferm. 2008;17(4):758-64.

12. Minayo, MCS. O desafio do conhecimento: pesquisa qualitativa em saúde. 11. ed. São Paulo: Hucitec, 2008.

13. Baralhas M, Pereira MAO. Concepções dos agentes comunitários de saúde sobre suas práticas assistenciais. Physis- Rev Saúde coletiva. 2011;21(1):31-46.

14. Jardim TA, Lancman S. Aspectos subjetivos do morar e trabalhar na mesma comunidade: a realidade vivenciada pelo agente comunitário de saúde. Interface (Botucatu). 2009;13(28):123-35.

15. Bachilli RG, Scavassa AJ, Spiri WC. A identidade do agente comunitário de saúde: uma abordagem fenomenológica. Ciên Saúde Coletiva. 2008;13(1):51-60.

16. Santos KT, Saliba NA, Moimaz SAS, Arcieri RM, Carvalho MD. Agente comunitário de saúde: perfil adequado a realidade o programa saúde da família?. Ciên Saúde coletiva. 2011;16(1):1023-28.

17. Nascimento EPL, Correa CRS. Agente comunitário de saúde: formação, inserção e prática. Cad Saúde Pública. 2008;24(6):1304-13.

18. Vasconcelos M, Grillo MJC, Soares SM. Práticas educativas em atenção básica à saúde. Tecnologias para abordagem ao individuo, família e comunidade. Belo Horizonte: Editora UFMG; NESCON, 2009.

Rev. Saúde (Santa Maria), Santa Maria, v.39, n.2

p.09-22, Jul./Dez.2013.

19. Carvalho CAP, Marsicano JA, Carvalho FS, Peres- Sales A, Bastos JRM, Sales-Peres SHC. Acolhimento aos usuários: uma revisão sistemática do atendimento no sistema único de saúde. Arq Ciência Saúde. ISSN 2236-5843 2008;15(2):93-5. 
20. Schmidel JPC. Formação do agente comunitário de saúde na reorganização da atenção primária com perspectiva de mudança do modelo de atenção. Escola Nacional de Saúde Pública Sergio Arouca. (Dissertação) Rio de Janeiro, 2009.

21. Bornstein VJ, Stotz EN. Concepções que integram a formação e o processo de trabalho dos agentes comunitários de saúde: uma visão da literatura. Ciênc saúde coletiva. 2008; 13(1):259-60.

22. Galavote HS, Prado TN, Maciel ELN, Lima RCD. Desvendando os processos de trabalho do agente comunitário de saúde nos cenários revelados na Estratégia Saúde de Família no município de Vitória (ES, Brasil). Ciênc saúde coletiva. 2011;16(1):231-40.

23. Santos IMV, Santos AM. Acolhimento no Programa Saúde da Família: revisão das abordagens em periódicos brasileiros. Rev salud pública, Bogotá. 2011;13(4):703-16.

24. Lunardelo SR. O trabalho do agente comunitário de saúde nos núcleos de saúde de família em Ribeirão Preto- São Paulo. Escola de Enfermagem de Ribeirão Preto- USP. (Dissertação), Ribeirão Preto, 2004.

25. Beck CLC, Minuzi D. O acolhimento como proposta de reorganização da assistência à saúde: uma análise bibliográfica. Saúde, Santa Maria. 2008; 34(1-2):37-43.

26. Ferreira VSC, Andrade CS, Franco TB, Merhy EE. Processo de trabalho do agente comunitário de saúde e a reestruturação produtiva. Cad Saúde Pública. 2009;25(4):898-906.

27. Medeiros FA, Araújo-Souza GC, Albuquerque-Barbosa AA, Clara-Costa IC. Acolhimento em uma Unidade Básica de Saúde: a satisfação do usuário em foco. Rev Salud pública, Bogotá. 2010;12(3):402-13.

28. Rodrigues AAAO, Santos AM, Assis MMA. Agente comunitário de saúde: sujeito da prática em saúde bucal em Alagoinhas, Bahia. Ciênc Saúde Coletiva. 2010;15(3):907-15.

29. Sossai LCF, Pinto IC, Mello DF. O agente comunitário de saúde (ACS) e a comunidade: percepções acerca do trabalho do ACS. Ciênc Cuid Saúde. 2010; 9(2):228-37.

30. Barros MMM, Chagas MIO, Dias MAS. Saberes e práticas do agente comunitário de saúde no universo do transtorno mental. Ciênc Saúde Coletiva. 2009;14(1):227-32.

31. Harada OL, Soares MH. A percepção do agente comunitário de saúde para identificar a depressão. SMAD, Rev Eletrônica Saúde Mental Álcool Drog. Ribeirão Preto. 2010; 6(2):315-336.

32. Dantas MBP, Silva MRF, Feliciano KVO. Subjetividade e dialogo na educação em saúde: práticas de agentes comunitários em equipe de saúde da família. Rev APS. Juíz de Fora. 2010; 13(4):432-44.

33. Lima CAB, Santos ALP, Gonçalves AM, Teixeira E, Medeiros HP. Representações sociais sobre educação em saúde de agentes comunitários: pistas para educação permanente. Cogitare Enferm. 2012; 17(1):15-20.

\section{Graziele Gorete Portella da Fonseca}

Endereço para correspondência - Rua General José Albano Leal, nº 124. Santa Maria, CEP: 97035340, RS, Brasil.

Currículo Lattes:http://lattes.cnpq.br/6112676439110625

E-mail:grazipf@yahoo.com.br

Recebido em 19 de fevereiro de 2013.

Aprovado em 16 de setembro de 2013.

Saúde (Santa Maria), v.39, n.2, p.09-22, 2013. 